\title{
\#SomosPatrimonio. Las transformaciones del patrimonio mundial: del tener al ser patrimonial
} \#WeareHeritage. World Heritage changes: from having to being heritage

\author{
Beatriz Santamarina (10 | Camila del Mármol" \\ Universitat de València. Valencia, Espanha \\ "Universitat de Barcelona. Barcelona, Espanha
}

\begin{abstract}
Resumen: En este artículo planteamos una reflexión teórica sobre los cambios en las políticas patrimoniales de la UNESCO y su incidencia en el imaginario y constructo patrimonial. En un contexto de nuevas aspiraciones, aparece el lema \#somospatrimonio. El cambio es considerable: no sólo se tiene patrimonio, sino que se puede llegar a ser patrimonio como un todo metonímico. El patrimonio puede ser (en su versión autorizada) o llegar a ser (en su versión democrática). En ese juego de ficciones se desvelan y se ocultan, se silencian o se proclaman las asimetrías y disfunciones de los capitales puestos en movimiento. En ese juego hemos pasado de 'tener' patrimonio, como contenedor de un tesoro ilustrado, a 'ser' patrimonio como fetiche de un mercado emergente. Aquí analizaremos el \#somospatrimonio como expresión que encapsula los nuevos tiempos patrimoniales, observando los contextos en los que se utiliza como una nueva marca identificativa al servicio del mercado o como una estrategia de reivindicación.
\end{abstract}

Palabras clave: Patrimonio inmaterial. UNESCO. Marcas patrimoniales. Comercialización. Turismo.

Abstract: In this article, we propose a theoretical reflection on the changes in UNESCO's heritage policies and their impact on the heritage imaginary and construct. The slogan \#WeareHeritage emerges within a context of new aspirations. The change is considerable: not only you have heritage, but you can become heritage as a metonymic whole. Heritage can be (in its authorized version) or become (in its democratic version). In this game of fictions, the asymmetries and dysfunctions of capitals set in motion are revealed and hidden, silenced, or proclaimed. This game has gone from 'having' heritage as a container for an illustrated treasure to 'being' heritage as a fetish of an emerging market. Here we will analyze \#WeareHeritage as an expression that encapsulates the new patrimonial times, observing the contexts in which it is used as a new identifying mark at the service of the market or as a strategy of vindication.

Keywords: Intangible heritage. UNESCO. Heritage brands. Commodification. Tourism.

Santamarina, B., \& Del Mármol, C. (2022). \#SomosPatrimonio. Las transformaciones del patrimonio mundial: del tener al ser patrimonial. Boletim do Museu Paraense Emílio Goeldi. Ciências Humanas, 17(1), e20210030. doi: 10.1590/2178-2547-BGOELDI-2021-0030 Autora para correspondência: Camila del Mármol. Universitat de Barcelona. Montalegre 608001 Barcelona, 08007 (cdelmarmol@ub.edu). Recebido em 01/04/2021

Aprovado em 11/06/2021

Responsabilidade editorial: Marília Xavier Cury 


\section{INTRODUCCIÓN}

En 2009 los medios de comunicación españoles se llenaron de titulares como este: "El tribunal de las aguas ya es patrimonio de la humanidad" (2009)1. Un año después volvía a repetirse el mismo titular: "El flamenco ya es patrimonio de la humanidad" (2010) o, más folklórico, "Olé por el flamenco: ya es patrimonio cultural inmaterial de la humanidad" (2010). Pasados los años, los titulares han seguido siendo los mismos: "Las fallas ya son patrimonio de la humanidad" (2016) o "Las tamborradas de Alzira y l'Alcora ya son patrimonio cultural inmaterial de la humanidad" (Cuquerella, 2018).

Desde una perspectiva acrítica del patrimonio que lo considere como una realidad dada, estas noticias no tendrían sentido. Nadie discutiría que las ruinas del Foro romano son patrimonio y, mucho menos, que son de la humanidad. ¿Qué sentido tendría, entonces, un titular de último momento anunciando 'El Coliseo ya es patrimonio Mundial'? La reflexión, aunque aparentemente sencilla, encierra los elementos políticos del constructo patrimonial. El coliseo es patrimonio, no puede llegar a serlo, o convertirse repentinamente, por definición es el patrimonio mismo (lo reencarna). Veámoslo en un titular de prensa de los primeros bienes españoles declarados Patrimonio Mundial: "La UNESCO incluye por primera vez monumentos españoles en la lista de bienes del patrimonio mundial" (Prieto, 1984). O, por dar un ejemplo más, atendamos a un bien específico: "La Lonja de Valencia es declarada Patrimonio Cultural de la Humanidad" (1996). En el primer caso, los cinco bienes se 'incluían', no habían llegado a ser, eran patrimonio que solo hacía falta listar. En el segundo, el edificio del gótico civil valenciano 'era declarado', pero el 'ya es patrimonio' carecía de sentido, porque se daba por supuesto.

Ahora bien, los medios de comunicación españoles no son los únicos que han reportado bajo estas fórmulas las inscripciones unesquianas. En dos continentes y países diferentes podemos encontrar los mismos encabezados. Veamos el caso de Argentina. En 2009 los medios porteños se inundaron de cabeceras como esta: "El tango ya es patrimonio de la humanidad" (2009) y seis años después se repetía el enunciado "El filete porteño ya es patrimonio de la humanidad" (2015). Sin embargo, si observamos los dos últimos bienes argentinos incorporados a la lista de Patrimonio Mundial (Casa Curutchet, 2016; Los Alerces, 2017) se repite el mismo patrón antes señalado: "El Parque Nacional los Alerces fue declarado Sitio de Patrimonio Mundial" (2017) o, más contundente, "La Casa Curutchet, la joya de La Plata que es patrimonio de la humanidad" (2018). Como leemos, la construcción de Le Corbusier 'es patrimonio' porque su consideración como máximo referente de la vanguardia en arquitectura lo hace de facto patrimonio (joya, en los términos utilizados, que remite a la concepción decimonónica de tesoro nacional). Estos titulares, junto con los últimos vistos en la prensa española, encajarían bien con la perspectiva sustancialista del patrimonio, donde la naturaleza patrimonial viene determinada por sus cualidades intrínsecas (Davallon, 2010; Sánchez-Carretero, 2017). Este enfoque, ampliamente extendido en distintas áreas del conocimiento, enfatiza la gestión y la protección de los ámbitos que se encasillan bajo la etiqueta del patrimonio cultural o patrimonio histórico, categorías que se redefinen, sobre todo, a partir de la segunda mitad del siglo XX (Smith, 2006; Poulot, 2006). En muchos contextos, el patrimonio colectivo ${ }^{2}$ ha sido definido como una simple derivación del concepto utilizado a nivel jurídico, es decir, el conjunto de bienes que una comunidad hereda del pasado o, en un sentido más amplio, la herencia cultural. No obstante, las definiciones de patrimonio varían mucho dependiendo

1 En 2009 la "Lista representativa del patrimonio cultural inmaterial de la humanidad" incluía nuevos bienes tras su activación. Hasta ese momento se había nutrido de los noventa bienes inscritos anteriormente como 'Obras Maestras del Patrimonio Oral e Intangible de la Humanidad'.

2 Nos inclinamos por utilizar el término patrimonio colectivo dado que el concepto de patrimonio cultural puede inducir a la confusión al asociarse con la definición humanista de cultura activada en el patrimonio decimonónico.

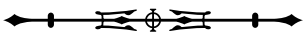


del campo disciplinario en el que nos encontremos. Desde las ciencias sociales, se ha puesto de manifiesto cómo el mismo hecho de declarar algo como patrimonio muestra una intervención social (Del Mármol \& Santamarina, 2017). Detrás de la misma se evidencian tanto una serie de requisitos como la necesidad de contar con agentes e instituciones que lo declaren como tal. Así, pese a su pretendida naturalización, esta visión rompe con cualquier pretensión esencialista. En los últimos años, numerosos autores han analizado el patrimonio como una práctica social, un ejercicio político por el cual elementos de la vida social pasan a ser entendidos bajo una nueva categoría o etiqueta edificada socialmente (Prats, 1997; Smith, 2006; Bendix et al., 2013). Volviendo a nuestras noticias podemos ver cómo distintos medios se esfuerzan en demostrar que el tribunal de las aguas, el flamenco, las fallas, las tamborradas, el tango o el filete 'ya son patrimonio de la humanidad', como si por arte de magia hubieran sufrido una transubstanciación. En todo caso, lo que pasó fue que estos 'elementos' (léase fiestas, tradiciones, prácticas sociales y culturales, fenómenos de sociabilidad local) pasaron a formar parte de la Lista Representativa del Patrimonio Cultural Inmaterial de la Humanidad. Aquí interesa subrayar que el 'ya es' implica en el presente una relación con el pasado, algo que se ha conseguido, que era potencialmente factible. El siguiente titular es indicativo de cómo se construye la inscripción de lo inmaterial al utilizar en su enunciado 'considerados' (posibilidad): "El reggae y las tamborradas, considerados patrimonio inmaterial de la humanidad" (2018). Los bienes, como podemos leer, no son, sino que pueden llegar a ser pensados como tales. Más categórico resulta este otro: "Lo declaró la UNESCO. El filete porteño ya es patrimonio de la humanidad" (2015). En este caso, el bien 'llega a ser' gracias a la intervención de la UNESCO, no por sí mismo (lo dijo la UNESCO).

El patrimonio puede ser (en su versión autorizada) o llegar a ser (en su versión democrática). En ese juego de ficciones se desvelan y se ocultan, se silencian o se proclaman las asimetrías y disfunciones de los capitales puestos en movimiento (García Canclini, 1993; Chaves et al., 2010); más si cabe hoy, que el patrimonio se ha convertido en un excepcional motor económico provocando un crecimiento y una demanda exponencial de las declaratorias (Heinich, 2009). Además, y en paralelo, hemos asistimos a una compleja institucionalización y burocratización de las prácticas de patrimonialización (Schmitt, 2009; Tauschek, 2013), dando lugar a actores e instituciones que modulan y acaparan el poder de definición poniendo en circulación novedosas formas patrimoniales. En este contexto de nuevas aspiraciones, aparece, en múltiples escenarios, el lema \#somospatrimonio. Fórmula construida en primera persona del plural (nosotros) y en presente indicativo (se da en el momento en el que se habla), que afirma del sujeto la cualidad (propiedades del ser) expresada por el atributo. El cambio es considerable: no sólo se tiene patrimonio, sino que se puede llegar a ser patrimonio como un todo metonímico.

En este artículo queremos plantear una reflexión teórica sobre los cambios en las políticas patrimoniales de la UNESCO y su incidencia en el imaginario y constructo patrimonial. Partiremos de considerar que el hoy llamado discurso patrimonial autorizado (Smith, 2006), no es otra cosa que la versión neoliberal, globalizada y hegemónica de la UNESCO, hija de la inicial concepción decimonónica (Choay, 1996; Poulot, 2006). El patrimonio como entelequia relacional, lejos de ser inmanente, se nos muestra como un artefacto cosificado capaz de responder a las demandas de cada contexto histórico: ora estado ora mercado (Santamarina \& Del Mármol, 2017). En ese juego hemos pasado de 'tener' patrimonio, como contenedor de un tesoro ilustrado (Fernández de Paz, 2006), a 'ser' patrimonio como fetiche de un mercado emergente (P. González, 2017). En este texto analizaremos precisamente el 'ya somos patrimonio' como expresión que encapsula los nuevos tiempos patrimoniales, observando los contextos en los que se utiliza como una nueva marca identificativa al servicio del mercado o como una estrategia de empoderamiento y reivindicación. 


\section{LAS TRANSFORMACIONES DE LA MAQUINARIA PATRIMONIAL}

Muchos autores coinciden en pensar el patrimonio no tanto como sustantivo sino como un proceso que selecciona una serie de elementos o características del pasado y las repiensa de cara al presente. Desde hace tiempo la antropología se aleja de consideraciones esencialistas y se refiere a procesos de patrimonialización y regímenes patrimoniales (Roigé \& Frigolé, 2010; Bendix et al., 2013; Harrison, 2013; De Cesari, 2013; Chaves et al., 2014; Geismar, 2015; Coombe \& Weiss, 2015); observando el patrimonio como proyecto político e ideológico (Kuutma, 2013; Tauschek, 2013). El concepto de regímenes patrimoniales, como argumenta Geismar (2015), nos permite abordar el patrimonio como un campo de gobernanza y política en lugar de una 'cosa' o 'entidad'. Además, debemos tener presente que el ". . heritage is not primarily about the past, but, instead, about our relationship with the present and the future" (Harrison, 2015a, p. 309).

Visto así ". . . los discursos del patrimonio son en realidad el desarrollo, encadenamiento o diversificación de diferentes discursos de conservación, restauración, salvaguardia y protección de elementos que al ser seleccionados ganan una nueva significación" (Del Mármol, 2017, p. 35). Esto obliga a resituarlo como proceso en sus condiciones históricas, económicas, políticas y afectivas de producción, entendiendo que es siempre una realidad histórica. Evidentemente, las condiciones de producción del patrimonio son múltiples, y tendríamos que extendernos en consideraciones sociohistóricas, políticas y económicas para entender la evolución y transformación del concepto desde el siglo XIX en adelante ${ }^{3}$. Si el patrimonio como uso del pasado desde el siglo XIX se relaciona con los procesos de producción de la nación ${ }^{4}$, hoy asistimos a un cambio en las cadencias, situándose el mercado como un gran demandador patrimonial (Del Mármol \& Santamarina, 2019).

No es nuestra intención realizar una lectura diacrónica del andamiaje patrimonial, tan sólo atenderemos a su particular globalización en la medida en que transforma parte de su gramática. Desde una perspectiva de análisis global, debemos referirnos a condiciones de producción planteadas por los discursos hegemónicos del patrimonio (Smith, 2006; Byrne, 1991) que han dado lugar a una versión autorizada impregnada de conceptos e imaginarios occidentales (García Canclini, 1990; Labadi, 2007; Pavone, 2008; Winter, 2014). Estas lógicas y discursos burocratizados vieron la luz con la UNESCO logrando su máximo esplendor con el crecimiento sostenido de esta institución y de sus diferentes convenciones (Arizpe, 2004; Nielsen, 2011).

La intensa tarea desplegada por la UNESCO se ha centrado en definir los sentidos normativos y performativos del patrimonio, así como sus campos, ámbitos y agentes creando todo un cuerpo especializado de técnicos y un potente mercado patrimonial. Esta ascendencia ha contribuido al establecimiento y desarrollo de los regímenes patrimoniales y de sus maquinarias (Bendix, 2009). La UNESCO ha sido esencial por su labor para la conservación, salvaguardia y difusión del patrimonio y por su cometido para la definición y el establecimiento de bienes patrimoniales. De un lado, este organismo ha impuesto la noción de patrimonio, exportándola y colonizándola frente a otras formas posibles de representación del pasado (Martín-Barbero, 2000; Herzfeld, 2004)5. De otro, las categorías impuestas han tenido efectos materiales e inmateriales, configurándose

3 Para una aproximación a su recorrido se pueden ver, entre otros, Choay (1996); González-Varas (1999); Hernández (2002); Hernàndez et al. (2005); Poulot (2006).

${ }^{4}$ La creación de una comunidad imaginada, en términos de Anderson (1983), necesita de una memoria compartida. En ese sentido, la producción de la nación necesita de la producción de un patrimonio colectivo.

5 Tal y como señala Harrison ". . . the technical standards might be considered to represent a material intervention which remakes the world in quite specific ways" (Harrison, 2015a, p. 304).

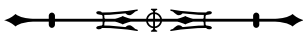


un mapa mundial de distribución patrimonial, donde el mercado globalizado dispone de lo patrimonial como un activo económico de primer orden (Bendix, 2009; Meskell et al., 2015). En cualquier caso, el poder de mostrar los patrimonios colectivos como entidades naturalizadas tiene la capacidad de presentarlos como procesos no supeditados a sus condiciones sociales de producción.

\section{POLÍTICAS PATRIMONIALES MUNDIALES}

Empezaremos aquí afirmando que el patrimonio y sus usos no están exentos de conflictos, pese al trabajo incesante de su naturalización. Su relación directa con la propiedad y titularidad de los bienes deviene siempre en problemáticas. La capacidad de apropiación, acción de adueñarse, o de expropiación, transferencia coercitiva, de lo patrimonial por agencias especializadas se ha producido a lo largo de su institucionalización (local, nacional o internacional). En el caso que nos ocupa, es especialmente significativa la apropiación y expropiación de los bienes en la medida en el que el sujeto receptor es abstracto, la humanidad, e inclusivo, lo nuestro.

En la definición de Patrimonio Mundial, a partir de la "Convención sobre la protección del patrimonio mundial, cultural y natural" (1972), se instaura como beneficiario un sujeto abstracto ${ }^{6}$ en un territorio indefinido (mundo). En este sentido, la convención rompe con la noción clásica del patrimonio (localizado y territorial) dando comienzo a la expansión de la cosmocultura, tomando el término de Arizpe (2004), o de la producción metacultural, siguiendo a Kirshenblatt-Gimblett (2004), translocalizada. Con ella, la UNESCO distingue y reconoce la existencia de patrimonios que no pueden ser titularidad sólo de unos cuantos, si no que deben ser subsumidos y tutelados por un ente global superior. El argumento esgrimido para esta operación bascula entre dos proposiciones. La primera se articula en la pretendida existencia de unos bienes sobresalientes que contienen un "valor excepcional universal" (Organización de las Naciones Unidas para la Educación, la Ciencia y la Cultura, 1972, p. 1). Esta declaración en sí misma es problemática, porque da por hecho la existencia de unos valores globales compartidos (Choay, 1996; Labadi, 2007). En realidad, con esta afirmación, la UNESCO presentaría su traducción particular de la globalización, articulada en los valores del proyecto del humanismo científico occidental (Pavone, 2008). La segunda se construye bajo la persuasión de la urgencia y la retórica del riesgo. Así, aparece la necesidad paternalista de garantizar a la ciudadanía global la posibilidad de disfrutar de unos bienes que por derecho (al ser universales) le corresponden (Organización de las Naciones Unidas para la Educación, la Ciencia y la Cultura, 1972). Recordemos que el impacto del movimiento internacional para la conservación de Abu Simbel, junto con otros templos nubios ante la construcción de la presa de Asuán, fue clave para poner en marcha la Lista de Patrimonio Mundial (Hernàndez et al., 2005). La asunción es, como vemos, realmente compleja, al convertir al sujeto patrimonial en un todo paradójico. Sí, en teoría, algo caracteriza al patrimonio es su capacidad para vertebrar las distintas identidades singularizadas (Prats, 1997), sean líquidas, fragmentadas o fracturadas (Hall, 2003, 2010; Bauman, 2004). Entonces, iCómo es posible construir una identidad universal basada en referentes comunes y compartidos? Desde nuestro punto de vista, solo puede resolverse afirmando que, efectivamente, no hay patrimonios mundiales sino 'patrimonializadores mundiales'. Patrimonializadores mundiales que, bajo el amparo de la UNESCO, ejercen un rol hegemónico en la gobernanza patrimonial reproduciendo en sus estructuras las lógicas del poder político-económico (Askew, 2010; Meskell \& Brumann, 2015).

El concepto abstracto de patrimonio mundial ha dado lugar a diferentes análisis desde variadas disciplinas.

\footnotetext{
6 Mundial como aquel perteneciente o relativo a todo el mundo, según su definición en el diccionario de la Real Academia Española. En inglés y francés, el término se define de la misma manera al compartir la misma raíz etimológica.

7 Jugamos aquí con la idea de Montenegro (2010).
}

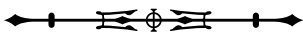


En nuestro caso, nos interesa poner el acento en el cambio de beneficiario, dado que "La notion de bien public mondial suppose implicitement que le patrimoine est la propriété de tous" (Benhamou, 2010, p. 126). Esto significa, en primer lugar, que nuevos actores reclaman la autoridad y la competencia para hablar en nombre de un patrimonio localizado, desplazando a los sujetos portadores en la asignación de valor y en la toma de decisiones. La aceptación de estructuras preceptivas globales sustituye, impone o produce, nuevos marcos normativos cargados de valores. En segundo lugar, implica un cambio en la propiedad, de ser posesión de algunos pasa a ser de todos. El desplazamiento de la titularidad patrimonial es substancialmente significativo, en cuanto da entrada al conflicto por la definición del sujeto (de quién es) y objeto (qué es) patrimonial. Además de las posibles implicaciones que se derivan de su conservación: “. . . los Estados Parte en la presente Convención reconocen que constituye un patrimonio universal en cuya protección la comunidad internacional entera tiene el deber de cooperar" (Organización de las Naciones Unidas para la Educación, la Ciencia y la Cultura, 1972, p. 4). Lo que comporta una serie de exigencias en la toma de decisiones sobre lo que, en principio, sería propio.

La lista de Patrimonio Mundial -cultural, natural y mixto- tuvo su ampliación en el 2003 con la "Convención para la salvaguardia del patrimonio cultural inmaterial". En esta ocasión, se establecía la llamada "Artículo 16: lista representativa del patrimonio cultural inmaterial de la humanidad" (Organización de las Naciones Unidas para la Educación, la Ciencia y la Cultura, 2003, p. 7). El cambio de adjetivos, de 'mundial' a 'de la humanidad', no puede pasar desapercibido 8 . Por dos razones, la primera porque pese al esfuerzo reconocido por equiparar bienes y reparar desigualdades (Frey \& Pamini, 2010; Brumann, 2012;
Frey et al., 2013; Meskell et al., 2015) se establecían dos listas diferenciadas. La segunda porque con el cambio de adjetivo se reforzaba la naturaleza humana y el sujeto beneficiario (género humano). Por otra parte, en esta Convención ya no se hablaba de 'valor universal', desaparecía así esta premisa tras la primera tentativa por patrimonializar lo inmaterial. Recordemos que, en 1998, el Comité Ejecutivo de la UNESCO aprobaba los criterios para la declaración de "Obras maestras del patrimonio oral e inmaterial de la humanidad". En su reglamento se decía ". . . los espacios o formas culturales declarados obras maestras del patrimonio oral e inmaterial de la humanidad han de tener un valor universal excepcional" (Reglamento, 1998, punto 6.a). Resultaba poco admisible, en el 2003, seguir hablando de "valor universal excepcional". No sólo era difícil de casar con la propia definición consensuada sobre patrimonio inmaterial (Organización de las Naciones Unidas para la Educación, la Ciencia y la Cultura, 2003) sino también insostenible por todas las críticas vertidas sobre el eurocentrismo y el occidentalismo de la institución (Audrerie et al., 1998; Labadi, 2007; Choay, 1996; Pavone, 2008).

Algunos autores sostienen que el hecho de no incluir el valor universal excepcional hace que:

The 2003 Convention was thus deliberately more modest in its key wording than both the 1972 World Heritage Convention and the 1998 Masterpiece Proclamation Programme. The list as a whole must be representative, but each individual cultural tradition does not need to be of outstanding universal value (Schmitt, 2008, p. 102).

Desde nuestro punto de vista, la redacción de la Convención del 2003 fue exquisita en lo formal, o si se prefiere políticamente correcta, en cuanto al cuidado de los valores, la titularidad y los beneficiarios, intentando responder, de este modo, a un aluvión de críticas que venían tanto de dentro como de fuera del organismo

\footnotetext{
8 En el preámbulo de la Convención del 1972 se utilizaba la expresión “. . . patrimonio mundial de la humanidad. . . ” (Organización de las Naciones Unidas para la Educación, la Ciencia y la Cultura, 1972, p. 1). Esta redundancia sólo tiene sentido si hace referencia a un concepto espacial (mundial) y a la titularidad (humanidad). Desde entonces en castellano, se han utilizado indistintamente ambos adjetivos en distintos ámbitos, pero el uso de patrimonio de la humanidad normalizado vino de la mano de la convención del 2003.
}

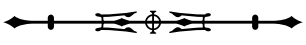


(Bertacchini et al., 2017). El problemático 'valor universal excepcional' fue sustituido por 'prácticas ejemplares' (Organización de las Naciones Unidas para la Educación, la Ciencia y la Cultura, 2003). Esta denominación tampoco escapó de las críticas y, en 2009, la UNESCO puntualizaba:

\begin{abstract}
Aunque la noción de "representatividad" se presta a diversas interpretaciones, es imprescindible comprender que la Convención se basa en la firme convicción de que todos los elementos del patrimonio cultural inmaterial revisten una misma importancia por el hecho de constituir un valor intrínseco para las comunidades interesadas, y no pretende en modo alguno fomentar una noción cualquiera de jerarquía. Por otra parte, la inscripción no significa de por sí que un elemento inscrito en la Lista tenga más importancia cultural que otro no inscrito en ella (Organización de las Naciones Unidas para la Educación, la Ciencia y la Cultura, 2009, p. 11).
\end{abstract}

Esta declaración quizás peca de excesivamente inocente porque es obvio que cualquier clasificación implica una jerarquización y, por tanto, siempre tiene un carácter arbitrario (Goody, 1977). En todo caso, el cambio de 'valores universales' a 'ejemplaridad' marcaba, pese a que sólo fuera en el plano de lo discursivo, un claro viraje. Lo mismo sucedía en relación a la intervención sobre el patrimonio: se puntualizaba y se recogía que ". . . los Estados Partes reconocen que la salvaguardia del patrimonio cultural inmaterial es una cuestión de interés general para la humanidad y se comprometen, con tal objetivo, a cooperar. .." (Organización de las Naciones Unidas para la Educación, la Ciencia y la Cultura, 2003, p. 8). Observamos también aquí un giro importante en el enunciado, de ser un patrimonio universal a ser un patrimonio de interés universal.

Sin embargo, todas estas transformaciones apenas han tenido impacto en los imaginarios y en las políticas implementadas. El sello 'Patrimonio Mundial' o 'Patrimonio de la Humanidad' marida bien con las nuevas demandas del mercado y el crecimiento exponencial del turismo cultural (World Tourism Organization, 2018). Hoy ingresar un bien, del tipo que sea, en las listas UNESCO garantiza obtener una marca de gran valor inmaterial, altamente cotizado y en alza, que permite entrar en la disputa por las topografías imaginadas y por los productos de calidad turística (Santamarina \& Del Mármol, 2020).

\section{LAS CONJUGACIONES PATRIMONIALES}

En 1972, la UNESCO establecía un sistema de conservación patrimonial (mundial) basado en una competencia velada y en una declaración de bienes bajo la lógica de la escasez capitalista. Los países podían tener o no tener patrimonio en función del pasado, la memoria y las narrativas ensambladas por el organismo. Las aspiraciones, por tanto, eran limitadas para algunos países en función de los bienes atesorados ${ }^{9}$. El patrimonio defendido era más que autorizado, autoritario (en el sentido de fundado en el principio de autoridad); y era definido como objetivable, tangible y elevado a bien universal. No es de extrañar entonces que las declaraciones fueran leídas desde los medios de comunicación con titulares similares 'el bien x es declarado Patrimonio Mundial'. En 2003, el giro copernicano dado por la institución permitió no solo tener (carácter acumulativo) sino también llegar a ser patrimonio (carácter ontológico). En realidad, este viraje comportaba nuevas conjugaciones para el constructo patrimonial abriendo nuevas posibilidades y desafíos. Si esto es así, entonces, ¿Cómo se articulan los nuevos patrimonios que no son, sino que llegan a ser?

Volvamos al comienzo de nuestro artículo, donde bienes inmateriales alejados por miles de kilómetros eran inscritos en la Lista de Patrimonio Inmaterial y presentados en los medios como logros ('ya son'). Atendamos, ahora como muestra, a lo sucedido en España. El 2010 puede considerarse como un año del 'éxito unesquiano' para la diplomacia española. El 16 de noviembre, el Comité

\footnotetext{
9 Al margen de otros problemas añadidos como la burocratización y la posición dentro del organismo. Arnáiz et al. (2019, p. 5) advierten de "la farragosa burocracia" y "la diferencia de recursos y posibilidades entre países" lo que genera una mayor desigualdad.
} 
Intergubernamental de la UNESCO reunido en Nairobi $(\text { Kenia })^{10}$, incorporaba, de golpe, cinco bienes a la "Lista representativa del patrimonio cultural inmaterial de la humanidad", tras presentar España tres candidaturas en exclusiva -el Flamenco (Andalucía, Extremadura y Murcia), el 'Castells' (Catalunya) y el Canto de la Sibila (Mallorca)- y otras dos pluriestatales compartidas -la Dieta Mediterránea y la Cetrería-. Apenas 15 días después de la decisión de la UNESCO, el 2 de diciembre del 2010, se organizaba en el emblemático Museo Nacional Centro de Arte Reina Sofía"1 de Madrid, una gala para festejar por todo lo alto 'el premio a la cultura española'. Con orgullo patriótico la fiesta celebró 'somos patrimonio' (Roldán, 2010). Para mayor empaque, el acto estuvo presidido por dos ministras del gobierno, la de Cultura y la de Medio Ambiente, y contó con una amplia representación de las instituciones autonómicas involucradas en las declaratorias y por diversos sectores culturales. No faltaron, entre otras, actuaciones flamencas, exhibiciones de silbo gomero, representaciones del canto de la Sibila y una exaltación a la dieta mediterránea, con demostraciones de platos a cargo de un prestigioso chef español. Por primera vez se hablaba de 'somos patrimonio'. El internacional artista, Paco de Lucía, empleaba también, para congratularse por la distinción del flamenco, esta misma expresión. En su foro oficial podía leerse textualmente: "iiiiiiiiiiiiiSomos Patrimonio de la Humanidad!!!!!!!” (2010). Como vemos, ya no se trataba de tener, en principio y por principio excluyente, se trataba de lograr ser. A lo largo de los siguientes años, volvemos a encontrar en España su empleo para festejar los bienes inmateriales ingresados en las listas de Patrimonio de la Humanidad. El uso de 'somos patrimonio' deviene especialmente significativo, porque simbólicamente pareciera que la UNESCO acreditará la excepcional calidad humana de sus portadores al adquirir la propiedad.

En 2011, se volvía a celebrar con júbilo la incorporación de La Festa de la Mare de Déu de la Salut d'Algemesín (Comunitat Valenciana). El alcalde de la localidad en el "Butlletí d'Informació Municipal" diriǵa una carta a sus ciudadanos para hacerles saber que eran patrimonio: 'Todos somos patrimonio'. En la misma, afirmaba que Algemesí había entrado ". . . en la lista exclusiva de ciudades que tienen el sello Patrimonio de la Humanidad" (Berca, 2011-2012). Un año después, le tocaba el turno a la Fiesta de los Patios de Córdoba (ver United Nations Educational, Scientific and Cultural Organization, 2012) (Andalucía). En 2015, aprovechando este nuevo ingreso, el ayuntamiento andaluz ponía en marcha el proyecto 'Somos patrimonio'13 con el objetivo de fomentar el empleo a través del turismo, llenando las redes con la etiqueta \#somospatrimonio ${ }^{14}$.

En 2016, las fiestas de las fallas lograban el ansiado reconocimiento de la UNESCO, después de un periplo de largas negociaciones, elaboración de expedientes y sesiones interminables de trabajo ${ }^{15}$.

10 Ver Organización de las Naciones Unidas para la Educación, la Ciencia y la Cultura (2010).

11 No deja de ser significativo que para celebrar la inclusión de los bienes inmateriales se eligiera para el evento un museo ligado a la alta cultura y la vanguardia.

12 Ver United Nations Educational, Scientific and Cultural Organization (2011). Ese mismo año se incluía también en el Registro de la Buenas Prácticas de Salvaguardia la 'Revitalización del saber tradicional de la cal artesanal en Morón de la Frontera'.

13 Ver más en "El flamenco y los patios de la zona urban Sur, objeto de estudio y emprendimiento de 'Somos Patrimonio'” (2015). Esta actuación estaba incluida en el marco del Proyecto Urban Sur, cofinanciado por la Unión Europea (UE) con cargo al Fondo Europeo de Desarrollo Regional (FEDER), al amparo de la Iniciativa Urbana prevista dentro del Eje 5 de 'Desarrollo sostenible urbano y local del Programa Operativo FEDER 2007-2013 de Andalucía, y por el Ayuntamiento de Córdoba.

14 La primera vez que aparece la etiqueta en twitter \#somospatrimonio vinculada a la UNESCO fue en febrero de 2015 en referencia al Carnaval de Barranquilla.

15 Desde 2011 las autoridades valencianas habían intentado presentar el expediente a la UNESCO. Por distintas razones políticas y por el cambio en el sistema de elección de las candidaturas del organismo internacional (solo una por estado), las fallas tuvieron que esperar para ser finalmente elegidas por España para su reconocimiento como Patrimonio de la Humanidad.

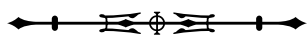


Las redes vitoreaban la inscripción con los hashtags \#somospatrimonio y \#fallasUNESCO. Nuevamente, no sólo se celebraba acaparar un bien más declarado Patrimonio de la Humanidad, se festejaba el ser patrimonio. De hecho, desde el ámbito político, se reforzaba esta idea: "L'enhorabona valencianes i valencians. Falleres i fallers! \#SomPatrimoni \#fallesUNESCO"16. Y la Junta Central Fallera, organismo centralizado que regula y coordina la fiesta, anunciaba de este modo la inscripción: "No es un sueño, somos Patrimonio" (2016).

La incorporación ontológica del patrimonio como marcador identitario se extendió posteriormente más allá del patrimonio inmaterial. En abril del 2019, el gobierno español se explayaba en el patrimonio como parte del ser, creando el dominio 'Somos Patrimonio'. Los medios de comunicación se hacían eco de la iniciativa: "El Ministerio de Cultura y Deporte ha lanzado la campaña 'Somos Patrimonio' con el objetivo de promocionar el patrimonio cultural español, dado que España está entre los países del mundo con más patrimonio cultural reconocido por UNESCO" ("El Ministerio de Cultura lanza la campña 'Somos Patrimonio'”, 2019).

En la primera página de la web aparece el siguiente texto: "España tiene 48 tesoros: 48 ciudades, paisajes, monumentos reconocidos por la UNESCO como Patrimonio Mundial. Es el tercer país del mundo en número de bienes con este reconocimiento. Descúbrelos en esta web y ive a conocerlos!" (Ministerio de Cultura y Deport, n.d.). A modo de mandato o deseo, 'ive a conocerlos!', indicaba el por qué de su puesta en marcha: el turismo. La estrecha relación entre patrimonio y turismo, el crecimiento en paralelo de ambos y el patrimonio como catalizador de los destinos ha sido ampliamente señalado (Korstanje, 2012, 2019; Fyall \& Rakic, 2006; Timothy, 2018). Más aún cuando entra en juego el sello de la UNESCO por su capacidad de atracción, de ahí que se cuestionen las motivaciones de activaciones en las listas unesquianas (Hall \& Piggin, 2003; Ryan \& Silvanto, 2010, 2011; Lai \& Can-Seng, 2015; Grätzer et al., 2015).

En este caso, la marca 'somos patrimonio' quedaba reducida a los bienes listados como Patrimonio Mundial, olvidando el patrimonio inmaterial reconocido por la UNESCO ${ }^{17}$. Con todo, lo más interesante de esta campaña es el video promocional. En el encabezamiento de la página dónde se inserta, y a modo de preámbulo, puede leerse: "i48! Solo Italia y China tienen más tesoros reconocidos como Patrimonio Mundial por la UNESCO. Pero hay una cosa que hace del patrimonio español algo absolutamente único. Ningún país consigue reunir tanta mezcla de culturas como España" (Ministerio de Cultura y Deport, n.d.). Volveremos luego a esta última sentencia, porque ahora resulta revelador un análisis del video: su puesta en escena, los personajes, los iconos y el discurso que le acompañan.

El vídeo comienza con la imagen de una gran biblioteca circular $^{18}$, en semipenumbra, creando una atmósfera propia para la teatralización y el misterio. En este escenario, aparece un docente, vestido de negro y con americana para mayor solemnidad, y se coloca delante un atril iluminado por un foco para centrar la atención e iniciar la lección magistral (Ministerio de Cultura y Deport, n.d.). Con voz grave y rostro serio se enfrenta a un grupo de estudiantes (universitarios) ${ }^{19}$ para hablar del patrimonio de España. El profesor universitario, léase la autoridad institucional de mayor prestigio, comienza:

\footnotetext{
16 Tweet del concejal de Cultura Festiva del Ayuntamiento de Valencia tras conocerse la inscripción de las fallas a la Lista de Patrimonio de la Humanidad. Ver Fusete (2016).

17 Este hecho es indicativo de la jerarquía establecida en los bienes, dando cuenta del peso todavía en el imaginario de lo qué es patrimonio colectivo.

18 No está de más señalar que los museos o bibliotecas son considerados los antecedentes institucionales del patrimonio (M. González, 1994; Ballart, 1997; González-Varas, 2003).

19 Por el contexto y la edad.
}

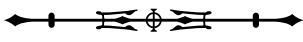


"España tiene $47^{20}$ tesoros reconocidos por la UNESCO como Patrimonio de la Humanidad. Es difícil definir nuestro patrimonio porque. . . . no somos de nada en concreto y somos un poco de todo" (Ministerio de Cultura y Deport, n.d.). Ante caras de asombro y gestos aburridos, el discurso se ilumina con modernas imágenes de dibujo, diseñadas para enlazarse, con un colorido llamativo que va esbozando los perfiles de los numerosos bienes ${ }^{21}$ a los que se refiere el orador:

Somos cañones, somos volcanes, somos bosques, somos pintores de cuevas, cazadores recolectores, flamencos, palmeras, somos fenicios, somos romanos, somos mediterráneos, somos cristianos, judíos, musulmanes, somos románicos, mudéjares, góticos, hispanoamericanos, somos hijos del renacimiento, barrocos, modernistas, caminantes y peregrinos, somos fareros que tienden puentes. Somos patrimonio (Ministerio de Cultura y Deport, n.d.).

Un estudiante ${ }^{22}$ con asombrado interés pregunta: "itodo esto pertenece a España? No, no exactamente - replica el profesor en tono trascendental- es de la Humanidad" (Ministerio de Cultura y Deport, n.d.). Tras esta sentencia, aparece en grande "somos patrimonio", con la aparición de un subtítulo, segundos después, "Monumentos, paisajes, ciudades, universidades" (Ministerio de Cultura y Deport, n.d.). Finalmente, el vídeo concluye con un claro mensaje: "España, tercer país del mundo en bienes declarados Patrimonio Mundial", apareciendo de fondo un mapa con la situación de los bienes (Ministerio de Cultura y Deport, n.d.). En un juego multifacético distintas esferas se entrecruzan, reproduciéndose mutuamente. En apenas veinte segundos, podemos ver cómo se entreveran magistralmente múltiples categorías, jerarquizadas y ordenadas. Desde la apelación a la naturaleza (prístina), la prehistoria y la historia (orígenes míticos) pasando por nuestra supuesta religiosidad (no conflictiva, armónica) hasta llegar al arte en mayúsculas (activador del patrimonio decimonónico). Y, por último y como colofón, aparece la luz (faro) y la metáfora del puente, un guiño a la armonía del país y la abertura a las culturas.

La celebración de la integración del ser patrimonial en el entramado abstracto 'de la Humanidad' (no pertenece a España, sino que 'somos patrimonio' y pertenecemos a la Humanidad) se conjuga con un claro posicionamiento del país en el mercado, aplaudiendo el tan preciado tercer puesto en la lista de declaraciones mundiales, a modo de ranking de calidad. En este contexto, la diferencia y no la distinción, entra en juego. Recuperemos ahora el enunciado antes aparcado: "Ningún país consigue reunir tanta mezcla de culturas como España" (Ministerio de Cultura y Deport, n.d.). Esta sentencia adquiere un nuevo significado si lo pensamos en relación al auge y exaltación del turismo cultural en las últimas décadas. Según la Organización Mundial del Turismo (UNWTO), el turismo cultural 'está destinado a seguir siendo uno de los mercados turísticos clave en el futuro' (World Tourism Organization, 2018, p. 12). Al respecto, algunos autores han destacado cómo hoy es el segmento de mayor valor, considerando a la cultura como el 'nuevo petróleo' (Richards, 2014, 2019).

Siguiendo los preceptos soteriológicos de la UNESCO (Stoczkowski, 2009), el conocimiento y valorización de las distintas culturas - por lo menos aquellas que tengan a bien mostrarse tolerantes, inclusivas, respetuosas y democráticas - contribuye al desarrollo de relaciones internacionales pacíficas, y, en última instancia, a la paz en el mundo (Nielsen, 2011; Di Giovine, 2009).

\footnotetext{
${ }^{20}$ La contradicción en el número de bienes declarados patrimonio es de la web.

${ }^{21}$ Es interesante anotar que sólo aparecen dos veces figuras humanas. En una, en realidad, se intuye porque sólo salen unas manos sosteniendo una cámara fotográfica (como mojón de lo que se persigue). En la otra, se dibuja a un peregrino del camino de Santiago de Compostela (se identifica por la concha prendida en la mochila) (Ministerio de Cultura y Deport, n.d).

22 No podemos pasar por alto la relación de género y patrimonio. Los dos personajes con voz son masculinos. Tal y como señala Smith (2008, p. 161) 'Heritage is gendered'. Y éste es masculino. El patrimonio se construye, reproduce y legitima bajo una visión androcéntrica, sexista y patriarcal.
}

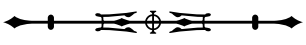


Paralelamente, el conocido como 'turismo cultural'23 ha sido aplaudido como una alternativa sofisticada ante los peligros de la masificación turística ${ }^{24}$. Para el posicionamiento en este anhelado mercado, que dibuja un paisaje aspiracional y emocional compuesto por cultos visitantes invirtiendo en el desarrollo local, la marca 'mezcla de culturas' es fundamental. Más allá de las muchas discusiones que podría causar a nivel político, en una España atravesada por nuevos fundamentalismos ${ }^{25}$, la frase: "somos cristianos, judíos, musulmanes. . ." (Ministerio de Cultura y Deport, n.d.), está colocada estratégicamente en mitad del texto y escoltada por el 'somos mediterráneo' (donde se sitúan las diferentes creencias) y por los estilos de arte medievales (románicos, mudéjares, góticos) que desvían oportunamente la mirada hacia el pasado idealizado de convivencia confesional, remitiendo al llamado 'mito de al-Andalus' (FernándezMorera, 2006; Said, 2017) 26. Tampoco podemos pasar por alto la aparición de la condición de "hispanoamericanos" (Ministerio de Cultura y Deport, n.d.). Y está categoría, tal vez, sea la más forzada dentro del relato, neutralizándose entre estilos artísticos y movimientos culturales. Este gesto puede interpretarse como un 'puente' de cordialidad, dirigido hacia el potencial mercado hispano, que oculta la propia conflictividad de una pretendida e idealizada identidad hispanoamericana ${ }^{27}$.

De cualquier manera, el @somospatrimonio es indiscutible como apuesta para competir en el mercado mundial del turismo a través de la diferencia. Esta apuesta la encontramos repetida por la geografía mundial. Por poner un solo ejemplo, a miles de kilómetros, en Puebla (México), apenas cinco días después de iniciarse la campaña española, el 10 de abril de 2019, la Secretaría de Turismo, lanzaba la campaña en redes: "No somos playa, somos patrimonio"28 con vistas al turismo de temporada de Semana Santa. México es el país latinoamericano que más turistas recibe y el séptimo dentro de la clasificación de los 10 destinos que reciben el $40 \%$ del turismo mundial (World Tourism Organization, 2018, p. 9). En esta ocasión, la apuesta intentaba hacer frente al turismo de sol y playa, todavía predominante (Frejomil et al., 2017) de destinos nacionales e internacionales tan consolidados como Cancún, Riviera Maya o Los Cabos ${ }^{29}$. El spot promocional resaltaba los valores de este municipio interior del centro del país. En el texto publicitario se puede leer: "Viajar por. Puebla. Es un estado de ánimo. Vivir. Sentir. Probar en Puebla" (Monterrosas, 2019). Acompañado de múltiples imágenes en cascada de naturaleza, viajeros, fiestas,

${ }^{23}$ Para una revisión sobre el turismo cultural se puede acudir a Espeso-Molinero (2019).

${ }^{24}$ Numerosos autores han denunciado el maridaje turismo/patrimonio, alertando de la amenaza sobre los propios bienes declarados. Ver, por ejemplo, Ruiz Lanuza y Pulido (2015). La propia UNESCO se hizo eco de estos riesgos proponiendo el 'turismo sostenible' como una vía alternativa (World Heritage Centre, n.d.).

${ }^{25}$ Ver, por ejemplo, Delgado y Ramírez Fernández (2018) donde realizan un análisis en España de inmigración, islamización e islamofobia. Además, en el último apartado, ofrece una bibliografía reciente sobre este tema. En otro sentido, Said (2017) analiza el legado de alAndalus, y su importancia en la construcción de la identidad e historia española. A partir de este análisis, establece las diferentes posiciones políticas actuales basadas en las interpretaciones de la producción del conocimiento histórico.

${ }^{26}$ Como apunta Fernández-Morera (2006, p. 23), ". . . the problem with this belief is that it is historically unfounded, a myth. The fascinating cultural achievements of Islamic Spain cannot obscure the fact that it was never an example of peaceful convivencia". Las cursivas son del autor.

27 Sobre el pluralismo cultural y las identidades en Latinoamérica existe una amplísima literatura. Ver, entre otros, Bonfil Batalla (1992). Para una crítica al concepto de americanidad, ver entre otros, Quijano y Wallerstein (1992).

${ }^{28}$ Hay diferentes versiones del video, si bien el fondo y el contenido es casi el mismo. Aquí tomamos la difundida en twitter. Ver Monterrosas (2019).

${ }^{29}$ El primer destino turístico es México D.F., le siguen, en orden, los anotados. Tal y como indican Frejomil et al. (2017, p. 496): "El escenario geográfico ha cambiado a partir de los diez últimos años; a pesar de que sigue prevaleciendo el carácter atractivo de las playas para el turismo doméstico e internacional, el gobierno federal y, por correspondencia, la Secretaría de Turismo han redirigido la atención hacia el aprovechamiento de otros recursos turísticos; en este sentido, reconocen la conveniencia de . . . impulsar la innovación de la oferta y elevar la competitividad del sector [y] posicionar a México como un destino atractivo en segmentos poco desarrollados, como el turismo cultural, ecoturismo y aventura, salud, deportes, de lujo, de negocios y reuniones, y religioso. ...".

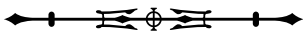


gastronomía, artesanía, deportes, etcétera. "Vivir, sentir y probar", apela a las emociones y a los sentidos, era su reclamo, su diferencia. Después se sentenciaba: "No somos playa. Somos patrimonio" (Monterrosas, 2019). Con más imágenes del centro histórico de la ciudad, de deportes de aventura en paisajes idílicos ${ }^{30}$ y con biblioteca antigua incluida se producía la invitación: 'Viaja a Puebla'. Meses después la prensa se hacía eco del éxito de la campaña: "Campaña 'No somos playa, somos patrimonio' detonó turismo en Puebla" (2019).

Ahora bien, el lema Somos patrimonio tiene un primer origen alejado de las propuestas anteriores. En el contexto iberoamericano, la Organización intergubernamental Convenio Andrés Bello (CAB) para fines educativos, científicos, tecnológicos y culturales se renovó en 199031. El convenio, suscrito por Bolivia, Chile, Colombia, Cuba, Ecuador, España, México, Panamá, Paraguay, Perú, República Dominicana y Venezuela, se estructuró a partir de distintas secretarías e institutos. Entre ellos el Instituto Iberoamericano del Patrimonio Natural y Cultural (IPANC), que sustituía al anterior Instituto Andino de Artes Populares (1977). Este cambio en la denominación condensa bien los giros experimentados por el patrimonio colectivo en las últimas décadas ${ }^{32}$. En 1997, lanzó el proyecto 'Somos patrimonio', como estrategia central del IPANC y del área de cultura del CAB, convocando el primer Premio Somos Patrimonio sobre los usos sociales del patrimonio ${ }^{33}$. Las reflexiones del jurado fueron presentadas por dos de sus miembros. Por un lado, Martín-Barbero (1998) lo hacía en un documento con un título tan expresivo como sugerente: "Patrimonio: el futuro que habita la memoria". En el mismo se entretejía una exposición de principios, una visión rupturista, epistemológica y ontológica del patrimonio, y una declaración política sobre los regímenes patrimoniales a partir de los 92 trabajos presentados al certamen. El 'estallido de las memorias', 'las conflictivas diferencias', 'el derecho de las colectividades a sus territorios e identidades' o 'la neutralización del espacio' del patrimonio nacional, daba paso a reclamar una nueva manera de construir el patrimonio colectivo, basada en la memoria activa, en el empoderamiento y en la participación de las comunidades. Por otro, Cerillos (1998, p. 1), en el "Prólogo" del libro del premio, insistía en la 'apropiación social del patrimonio' afirmando que ". . . no hay otra salida viable para recuperar el patrimonio que devolvérselo a la comunidad. . ."

En este contexto, reivindicar 'somos patrimonio' funcionaba como un dispositivo de intervención para la apropiación social y real y la autorreflexión de las comunidades sobre 'su' propio patrimonio. La incentivación a la reapropiación reconocía la práctica común de la confiscación y fiscalización sobre la conceptualización tradicional del patrimonio colectivo (gobiernos, instituciones y expertos). La solución para enfrentarse a los mecanismos de producción excluyente y exclusiva del patrimonio era, para este organismo, el recurso ontológico al 'somos patrimonio', la configuración definitiva de un aparato biopolítico a través del cual el sujeto tiene que pensarse como patrimonio, como dimensión inmanente de su ser. Tal y como señalaba Cerillos (1998, p. 1): “. . . saber quiénes somos para ser más fuertes." La apelación a 'ser', la diferencia y el reclamo de 'lo propio' se fundían en la exigencia del 'somos patrimonio'. Así, Martín-Barbero (1998, p. 3) acaba con un contundente alegato: ". . . no les suplanten ni usurpen en su irremplazable tarea de dar sentido y vigencia a lo que es suyo." No está de más recordar que se había publicado una compilación de artículos por Florescano (1993) sobre el patrimonio en México. Sin duda, su propia introducción, y textos como el de Bonfil Batalla(1993) o el de

\footnotetext{
30 Hoy la demanda de turismo exige la posibilidad de obtener experiencias múltiples en un mismo destino (Prats \& Santana, 2011; Kutzner \& Wright, 2010; Espeso-Molinero, 2019). Por ello, no llama la atención la aparición en el spot de deportes de aventura vinculados, por otro lado, al patrimonio natural, para completar la oferta patrimonial.

31 En realidad, sustituía al convenio firmado en 1970 en Colombia.

32 Para una aproximación a los cambios se puede acudir, entre otros, a Villarroya (2002) o Hernàndez et al. (2005).

33 Más información ver Convenio Andrés Bello (n.d.).
}

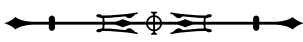


García Canclini (1993), habían generado un intenso debate sobre el 'laberinto de significados' y los 'usos sociales del patrimonio'. En el contexto, además, de una creciente crítica latinoamericana sobre la colonialidad del poder, del saber, del ser y del sistema mundo-moderno/colonial ${ }^{34}$. Obras como las de Benjamin, Foucault, Bourdieu o Wallerstein, entre otros, tuvieron una profunda impronta generándose una interesante bibliografía que ponía en jaque la versión impuesta del patrimonio decimonónico. Desde perspectivas mordaces y alejadas de una visión estética, estática y elitista, las prácticas e imaginarios del patrimonio hegemónico se analizaron como componentes cruciales del régimen poder eurocéntrico. La diferencia y la diversidad iban ganado terreno frente a la distinción en esta coyuntura, el somos patrimonio encapsulaba las reivindicaciones y expresaba la necesidad de empoderamiento frente a la desvalorización y la invisibilización de multitud de patrimonios. La reapropiación, la revalorización de conocimientos, prácticas, memorias e historias, localizadas y elaboradas por las comunidades, se enfrentaba a un patrimonio nacional e internacional (este último, pretendidamente, universal o de la humanidad).

Tras 45 años de la génesis de la CAB se presentaba un libro, a modo de balance, sobre su gestión. En cuanto al premio 'Somos patrimonio' se describían los dos pilares que los habían regido:

Primero, el patrimonio cultural no es sólo referencia del pasado sino que está asociado con la vida cotidiana de los pueblos, etnias, comunidades y naciones. Segundo, el patrimonio no tiene valor por sí mismo, sino por el que las sociedades y grupos humanos le asignan; consecuentemente, el patrimonio está en las personas y su valoración se va modificando en la medida en que las personas, los grupos, las sociedades están en cambio, en constante construcción y reelaboración [énfasis adicional] (Convenio Andrés Bello, 2015, p. 15).

En este fragmento (las cursivas son nuestras), la $\mathrm{CAB}$ volvía hacer una declaración de principios sobre el patrimonio colectivo haciéndose eco, implícitamente, de la Convención del 2003. Los usos del pasado se ensamblan en la cotidianidad, el patrimonio carece de sentido si no se le otorga y, por último, 'está en las personas'. El somos patrimonio, más que nunca, cobraba fuerza al adherirse la UNESCO a la dimensión ontológica de lo patrimonial. Pese a todo, y siendo en principio una llamada al empoderamiento, pronto se pusieron en marcha iniciativas para la promoción del patrimonio (por ejemplo, el programa 'Rutas del patrimonio') con el objetivo de incentivar su dimensión económica bajo el paraguas de la sostenibilidad (Convenio Andrés Bello, 2015, p. 81). Además, de forma explícita, la $C A B$ lo subrayaba en el enunciado de su último eje de actuación: "Propuestas de valoración social y económica del patrimonio" (Convenio Andrés Bello, 2015, p. 85). No deja de llamar la atención como la lectura ontológica del patrimonio se conjuga en estos ejemplos con su realización como valor en el mercado.

Para Harrison (2015b) es apropiado entender el patrimonio en términos de ontologías de conectividad (connectivity ontologies), como un espacio donde los futuros son ensamblados, un esfuerzo colaborativo, dialógico e interactivo compuesto de realidades discursivas y materiales. Se trataría entonces de un fenómeno universal, ya que estaría presente con distintas configuraciones en todas las sociedades y se centraría en el cuidado del pasado en el presente y hacia el futuro (Harrison, 2015a, 2015b). Si bien esta definición amplía las críticas constructivistas del patrimonio como andamiaje político-económico que se articula en la tensión de distintas esferas de poder, no deja de ser una categoría analítica que utiliza el concepto de patrimonio para identificar amplias esferas de la vida social (Collins, 2011; P. González, 2017). El patrimonio puede ser, como sostiene Harrison (2015b) en su énfasis ontológico, un espacio donde los futuros son ensamblados. Pero mientras estos futuros sean desarrollados dentro del

\footnotetext{
${ }^{34}$ Los trabajos de Escobar, Mignolo, Ribeiro o Quijano, entre otros, son representativos de ello. Para una aproximación, a las distintas perspectivas, se puede acudir a la compilación de Lander (2000).
} 
contexto de posibilidades del neoliberalismo no podemos ignorar que:

... en el patrimonio confluye así lo que podríamos llamar una acumulación primitiva de lo simbólico, convirtiéndose en un capital - que es la forma que adopta el patrimonio en el capitalismo desde su nacimiento como categoría - y en un instrumento de hegemonía que facilita la reproducción del capital gestionado por su garante: el estado (P. González, 2017, pp. 58-59).

Al insistir en ampliar el concepto de patrimonio para abarcar cada vez más ámbitos de la vida social contribuimos a un proceso de acumulación a partir del cual se permite la inclusión de un mayor número de esferas bajo la óptica patrimonial, ya demostradamente funcionando bajo la lógica del mercado (Bendix, 2009; P. González, 2014). La antropología ha ensayado distintas categorías para referirse a los usos del pasado para el presente y el futuro, categorías más amplias y menos determinadas que permiten reflexiones ontológicas sobre la memoria, el pasado, la historia y sus contribuciones a los modos de existencia ${ }^{35}$. Consideramos que hay riesgos si pensamos en términos de un ámbito expandido del patrimonio (Harrison, 2015b). El giro ontológico que analizamos en este artículo nos muestra un acopio clasificatorio expansivo, un proceso de acumulación de esferas que nos lleva a recuperar la idea del patrimonio como realidad transaccional (Harrison, 2018; Bennett, 2013; Foucault, 2010). En este sentido, el análisis se centra una vez más en las racionalidades de gobierno que son producidas a través de la mediación de sutiles dispositivos de poder que organizan, orientan y clasifican la vida social. Preparando el terreno para nuevas apropiaciones. El patrimonio puede ser un campo de ensamblaje de futuros alternativos (Harrison, 2018), siempre y cuando su análisis no pierda de vista la constitución de los regímenes patrimoniales en el complejo entramado de derechos, titularidades, recursos y subjetividades (Geismar, 2015) que actúan como pilares de nuestro sistema político-económico contemporáneo: ". . . it is clear that heritage is a fundamental process of value formation, linked more often than not to processes of objectification, exploitation, commoditization, and profit" (Geismar, 2015, p. 73).

\section{CONCLUSIÓN}

Al comienzo de nuestro artículo nos deteníamos en observar los enunciados de los medios de comunicación para ver el juego establecido entre el tener y el ser patrimonial. El salto ontológico se producía en distintos continentes y era una expresión más de las transformaciones sufridas en el aparato patrimonial. Durante las dos últimas décadas, especialmente, se ha puesto el énfasis en el papel de las comunidades como agentes con la capacidad de definir su patrimonio, en un intento de democratizar su constitución elitista. Este acento se ha traducido en una doble rotación produciéndose, por un lado, un giro hacia la multiculturidad (Chaves et al., 2010; Montenegro, 2013) y, por el otro, un giro hacia la participación (Cortés-Vázquez et al., 2017; SánchezCarretero et al., 2019). Ambos giros fueron exigencias, de largo recorrido, tanto para desvestir al patrimonio de las versiones sustancialistas y autoritarias, como para poner el acento en la diversidad cultural.

Desde la "Convención para la salvaguardia del patrimonio cultural inmaterial" (2003), los regímenes patrimoniales se han complejizado con la entrada de nuevos actores, instituciones, agencias y, sobre todo, con la impronta del mercado. El problema, tal y como señalan Chaves et al. (2010, p. 19), es que, en realidad, las cosas no han cambiado sustancialmente. Hoy la ". . . identidad, diversidad, diferencia, aparecen como activos económicos; como capitales." Y si bien estamos de acuerdo con esta afirmación, no es menos cierto que el patrimonio puede leerse como una oportunidad política (Santamarina \& Mompó, 2021).

\footnotetext{
35 Para un debate reciente ver Palmié y Stewart (2016).
} 
Desde el 2014, las redes sociales se han llenado de etiquetas \#somospatrimonio y, en numerosas ocasiones, ha sido para reclamar que un sinfín de bienes diversos se listara como patrimonio (desde un barrio, una fiesta, un uso, un edificio, una danza, hasta una comunidad, entre otros muchos). La CAB, no ha sido la única que ha exhibido el 'somos patrimonio' como formula reivindicativa. Pero, desde entonces, también es posible rastrear en las redes cómo el \#somospatrimonio ha sido un reclamo para invitar al turismo. Para Lacarrieu (2013, p. 97) “. . . el patrimonio no es solo consumo, espectáculo o recurso turístico, sino sobre todo una herramienta de poder." Y, como instrumento de poder, tiene la capacidad de definir y de neutralizar las demandas. En este sentido, queda mucho camino por andar. Tal y como reconocía la CAB hay que avanzar ". . . en la definición y efectividad de los derechos culturales pues el solo reconocimiento de la diversidad no es suficiente" (Convenio Andrés Bello, 2015, p. 88). Quizás, es hora, siguiendo a Harrison (2015b, p. 28), de poner en valor una pluralidad de ontologías alternativas con heterogéneas prácticas patrimoniales para ensamblar diferentes futuros, ". . . to sketch an ontological politics of and for heritage, a sense of how heritage could be oriented toward composing "common worlds" and "common futures". Sin olvidar cómo y bajo qué regímenes de poder se articula la producción de esos 'commons' (P. González, 2014).

\section{AGRADECIMIENTOS}

Este trabajo se ha desarrollado en el marco del siguiente proyecto de investigación: "Patrimonio inmaterial y politicas culturales: desafios sociales, politicos y museológicos", financiado por el Ministerio de Ciencia, Innovación y Universidades y el Programa FEDER (PGC2018-096190B-I00).

\section{REFERENCIAS}

Anderson, B. (1983). Imagined communities: Reflections on the origins and spread of capitalism. Verso.
Arizpe, L. (2004). Intangible cultural heritage, diversity and coherence. Museum International, 56(1-2), 130-136. https:// doi.org/10.1111/j.1350-0775.2004.00467.x

Arnáiz, M. M., Rodríguez, E. B., \& Hernando, F. M. (2019). Criterios de la UNESCO para la declaración de regiones vitícolas como paisaje cultural: su aplicación al caso español. Boletín de la Asociación de Geógrafos Españoles, 80(2614), 1-33. https:// doi.org/10.21138/bage.2614

Askew, M. (2010). The magic list of global status: UNESCO, World Heritage and the agendas of states. In S. Labadi \& C. Long (Eds.), Heritage and globalisation (pp. 19-44). Routledge.

Audrerie, D., Souchier, R., \& Vilar, L. (1998). Le patrimoine mondial. Presses Universitaries de France.

Ballart, J. (1997). El patrimonio histórico y arqueológico: Valor y uso. Ariel.

Bauman, Z. (2004). Identity: Conversations with Benedetto Vecchi. Polity Press.

Bendix, R. F. (2009). Heritage between economy and politics: An assessment from the perspective of cultural anthropology. In L. Smith \& N. Akagawa (Eds.), Intangible Heritage (pp. 253269). Routledge.

Bendix, R. F., Eggert, A., \& Peselmann, A. (2013). Heritage regimes and the state (Vol. 6). Göttingen University Press.

Benhamou, F. (2010). L'inscription au patrimoine mondial de l'humanité. Revue Tiers Monde, (202), 113-130.

Bennett, T. (2013). Making culture, changing society. Routledge.

Berca. (2011-2012). Butlletí d'Informació Municipal, (196). https://www.algemesi.es/sites/www.algemesi.es/files/ bercadesembre2011.pdf

Bertacchini, E., Liuzza, C., \& Meskell, L. (2017). Shifting the balance of power in the UNESCO World Heritage Committee: An empirical assessment. International Journal of Cultural Policy, 23(3), 331-351. https://doi.org/10.1080/10286632.2015.10 48243

Bonfil Batalla, G. (1992). Identidad y pluralismo cultural en América Latina. Fondo Editorial del CEHASS.

Bonfil Batalla, G. (1993). Nuestro patrimonio cultural: Un laberinto de significados. In E. Florescano (Comp.), El patrimonio cultural de México (pp. 28-56). Fondo de Cultura Económica.

Brumann, C. (2012). Multilateral ethnography: Entering the World Heritage arena. Max Planck Institute for Social Anthropology, (136), 1-17. 
Byrne, D. (1991). Western hegemony in archaeological heritage management. History and Anthropology, 5(2), 269-76. https:// doi.org/10.1080/02757206.1991.9960815

Campaña "No somos playa, somos patrimonio" detonó turismo en Puebla. (2019, julio 19). Unión Puebla. https://www. unionpuebla.mx/articulo/2019/07/19/turismo/campana-nosomos-playa-somos-patrimonio-detono-turismo-en-puebla

Cerillos, M. L. (1998). Prólogo. In Somos patrimonio (Experiencias de Apropiación social del patrimonio Cultural y Material) (pp. 1-2). Covenio Andres Bello. http://convenioandresbello.org/ cab/wp-content/uploads/2019/06/apropiacion.pdf

Chaves, M., Montenegro, M., \& Zambrano, M. (2010). Mercado, consumo y patrimonialización cultural. Revista Colombiana de Antropología, 46(1), 7-26.

Chaves, M., Montenegro, M., \& Zambrano, M. (Comps.). (2014). El valor del patrimonio: Mercado, políticas culturales y agenciamientos sociales. Instituto Colombiano de Antropología e Historia.

Choay, F. (1996). L'allégorie du patrimoine.Seuil.

Collins, J. (2011). Culture, content, and the enclosure of human being: UNESCO's "intangible" heritage in the new millennium. Radical History Review, (109), 121-135. http://dx.doi. org/10.1215/01636545-2010-019

Convenio Andrés Bello (Org.). (2015). Pasado, presente y futuro de somos Patrimonio: 45 años de acciones en patrimonio culturaly natural. CAB. http://convenioandresbello.org/cab/wp-content/ uploads/2019/06/Somos_Patrimonio_Informe_Final_Pasado Presente_Futuro_2015.p̄pdf

Convenio Andrés Bello. (n.d.). ¿Qué es el CAB. https:// convenioandresbello.org/cab/que-es-el-cab/

Coombe, R. J., \& Weiss, L. M. (2015). Neoliberalism, heritage regimes, and cultural rights. In L. Meskell (Ed.), Global heritage: A Reader (pp. 43-69). Wiley-Blackwell.

Cortés-Vázquez, J., Jiménez-Esquinas, G., \& Sánchez-Carretero, C. (2017). Heritage and participatory governance: An analysis of political strategies and social fractures in Spain. Anthropology Today, 33(1), 15-18. https://doi. org/10.1111/1467-8322.12324

Cuquerella, T. (2018, noviembre 30). Las tamborradas de Alzira y l'Alcora ya son patrimonio cultural inmaterial de la humanidad. El Diario. es. https://www.eldiario.es/cv/cultura/tamborradas-Alzirapatrimonio-inmaterial-humanidad_0_841315935.html

Davallon, J. (2010). The game of heritagization. In X. Roigé \& J. Frigolé (Eds.), Constructing cultural and natural heritage: Parks, museums and rural heritage (pp. 27-38). ICRPC.
De Cesari, C. (2013). Thinking through heritage regimes. In R. F. Bendix, A. Eggert \& A. Peselmann (Eds.), Heritage regimes and the state (pp. 399-413). Universitatsverlag Gottingen.

Del Mármol, C. (2017). Pasados locales, políticas globales: Procesos de patrimonialización en un valle del Pirineo catalá. Neopatria-AVA

Del Mármol, C., \& Santamarina, B. (2019). Seeking authenticity: Heritage and value within the intangible economy. Journal of Mediterranean Studies, 28(2), 117-132.

Delgado, V. T., \& Ramírez Fernández, Á. (2018). La antropología de los contextos musulmanes desde España: Inmigración, islamización e islamofobia. Revista de Dialectología y Tradiciones Populares, 73(2), 295-324. https://doi.org/10.3989/ rdtp.2018.02.002

Di Giovine, M. (2009). The heritage-scape: UNESCO, world heritage and tourism. Lexington Books.

El filete porteño ya es patrimonio de la humanidad. (2015, diciembre 1). Infobae. https://www.infobae.com/2015/12/01/1773565-elfilete-porteno-ya-es-patrimonio-la-humanidad/

El flamenco ya es patrimonio de la humanidad. (2010, noviembre 16). El País. https://elpais.com/cultura/2010/11/16/ actualidad/1289862006_850215.html

El flamenco y los patios de la zona urban Sur, objeto de estudio y emprendimiento de 'Somos Patrimonio'. (2015, agosto 31). 20 Minutos. https://www.20minutos.es/ noticia/2545098/0/flamenco-patios-zona-urban-sur-objetoestudio-emprendimiento-somos-patrimonio/\#xtor=AD$15 \&$ xts $=467263$

El Ministerio de Cultura lanza la campña 'Somos Patrimonio'. (2019, abril 5). ABC: Cultura. https://www.abc.es/ cultura/abci-ministerio-cultura-lanza-campana-somospatrimonio-201904051848_video.html

El Parque Nacional los Alerces fue declarado Sitio de Patrimonio Mundial. (2017, julio 7). La Nación. https://www.lanacion.com. ar/sociedad/el-parque-nacional-los-alerces-fue-declaradositio-de-patrimonio-mundial-de-la-humanidad-nid2040639

El reggae y las tamborradas, considerados patrimonio inmaterial de la humanidad. (2018, noviembre 29). Público. https:// www.publico.es/culturas/reggae-y-tamborradas-consideradospatrimonio-inmaterial-humanidad.html

El tango ya es patrimonio de la humanidad. (2009, septiembre 30). Clarín. https://www.clarin.com/ultimo-momento/tangopatrimonio-humanidad_0_SJIWsYuCaKl.html

El tribunal de las aguas ya es patrimonio de la humanidad. (2009, noviembre 1). Levante: El Mercantil Valenciano. https://www. levante-emv.com/portada-castello/2009/10/01/tribunal-aguaspatrimonio-humanidad/636988.html 
Espeso-Molinero, P. (2019). Tendencias del turismo cultural. Pasos: Revista de Turismo y Patrimonio Cultural, 17(6), 1101-1112. https://doi.org/10.25145/j.pasos.2019.17.076

Fernández de Paz, E. (2006). De tesoro ilustrado a recurso turístico: El cambiante significado del patrimonio cultural. Pasos: Revista de Turismo y Patrimonio Cultural, 4(1), 1-12. https://doi.org/10.25145/j.pasos.2006.04.001

Fernández-Morera, D. (2006). The myth of the Andalusian paradise. Intercollegiate Review, 23-31.

Florescano, E. (Comp.). (1993). El patrimonio cultural de México. Fondo de Cultura Económica.

Foucault, M. (2010). The birth of biopolitics: Lectures at the Collège de France, 1978-1979. Picador.

Frejomil, E. P., Crispín, Á. S., \& Sizzo, I. A. (2017). Niveles de selectividad territorial de los destinos turísticos en México. Cuadernos de Turismo, (39), 495-520. https://doi. org/10.6018/turismo.39.290671

Frey, B. S., \& Pamini, P. (2010). World heritage: Where are we? An empirical analysis. Working Paper Series, (462). https://dx.doi. org/10.2139/ssrn.1554892

Frey, B. S., Pamini, P., \& Steiner, L. (2013). Explaining the world heritage list: An empirical study. International Review of Economics, 60(1), 1-19. http://dx.doi.org/10.1007/s12232013-0174-4

Fusete, P. [@perefuset]. (2016, noviembre 30). L'enhorabona valencianes $i$ valencians. Falleres i fallers! \#SomPatrimoni \#fallesUNESCO. Twitter. https://twitter.com/perefuset

Fyall, A., \& Rakic, T. (2006). The future market for world heritage sites. In A. Leask \& A. Fyall (Eds.), Managing World Heritage Sites (pp. 159-75). Elsevier.

García Canclini, N. (1990). Culturas híbridas: Estrategias para entrar y salir de la modernidad. Grijalvo.

García Canclini, N. (1993). Los usos sociales del patrimonio cultural. In E. Florescano (Comp.), El patrimonio cultural de México (pp. 41-62). Fondo de Cultura Económica.

Geismar, H. (2015). Anthropology and heritage regimes. Annual Review of Anthropology, 44, 71-85. https://doi.org/10.1146/ annurev-anthro-102214-014217

González, M. I. (1994). Els gabinets del món: Antropologia, museus i museologies. Pagès Editors.

González, P. A. (2014). From a given to a construct: Heritage as a commons. Journal of Cultural Studies, 28(3), 359-390.
González, P. A. (2017). El antipatrimonio: Fetichismo y dominación en Maragatería. CSIC.

González-Varas, I. (1999). Conservación de bienes culturales: teoría, principios y normas. Cátedra.

Goody, J. (1977). The domestication of the savage mind. Cambridge University Press.

Grätzer, M., Rengard, M., \& Terlouw, F. (2015). The world heritage as a brand: Case study of world heritage brand usage by sites and their stakeholders in context of sweden and denmark. Linnaeus University.

Hall, S. (2003). Who needs 'Identity'? In S. Hall \& P. Gay (Eds.), Questions of cultural identity (pp. 1-17). Sage.

Hall, S. (2010). Identidad cultural y diáspora. In S. Hall, E. Restrepo, C. Walsh \& V. Vich (Eds.), Sin garantías: Trayectorias y problemáticas en estudios culturales (pp. 349-361). Envión Editores.

Hall, M., \& Piggin, R. (2003). World heritage sites: Managing the brand. In A. Fyall, B. Garrod \& A. Leask (Eds.), Managing visitor attractions: New directions (pp. 203-19). Routledge.

Harrison, R. (2013). Heritage: Critical approaches. Routledge.

Harrison, R. (2015a). Heritage and globalization. In E. Waterton \& S. Watson (Eds.), The palgrave handbook of contemporary heritage research (pp. 297-312). Palgrave Macmillan.

Harrison, R. (2015b). Beyond "natural" and "cultural" heritage: Toward an ontological politics of heritage in the age of Anthropocene. Heritage e Society, 8(1), 24-42. https://doi. org/10.1179/2159032X15Z.00000000036

Harrison, R. (2018). Conclusion: On heritage ontologies: Rethinking the material worlds of heritage. Anthropological Quarterly, 91(4), 1365-1384.

Heinich, N. (2009). La fabrique du patrimoine: De la cathédrale à la petite cuillère. Maison des Sciences de l'Homme.

Hernández, F. H. (2002). El patrimonio cultural: La memoria recuperada. Trea.

Hernàndez, G. M., Santamarina, B., Moncusí, A., \& Albert, M. (2005). La memoria construida: Patrimonio cultural y modernidad. Tirant Lo Blanch.

Herzfeld, M. (2004). The body impolitic: Artisans and artifice in the global hierarchy of value. University of Chicago Press.

Kirshenblatt-Gimblett, B. (2004). Intangible heritage as metacultural production. Museum International, 56(1-2), 52-65. https:// doi.org/10.1111/j.1350-0775.2004.00458.x 
Korstanje, M. (2012). Reconsidering cultural tourism: An anthropologist's perspective. Journal of Heritage Tourism, 7(2), 179-184. https://doi.org/10.1080/1743873X.2011.639883

Korstanje, M. (2019). Lo no-patrimoniable es invisible a la vista: La obsesión moderna por el patrimonio turístico. El Periplo Sustentable, (36), 432-446.

Kutzner, D., \& Wright, P. A. (2010). An investigation into key market segments for aboriginal tourism in northern British Columbia, Canada. Journal of Vacation Marketing, 16(2), 97-110. https:// doi.org/10.1177\%2F1356766709357487

Kuutma, K. (2013). Between arbitration and engineering: Concepts and contingencies in the shaping of heritage regimes. In R. F. Bendix, A. Eggert \& A. Peselmann (Eds.), Heritage regimes and the state (pp. 21-36). Universitätsverlag Göttingen.

Labadi, S. (2007). Representations of the nation and cultural diversity in discourses on World heritage. Journal of Social Archaeology, 7(2), 147-170. https://doi. org/10.1177\%2F1469605307077466

Lacarrieu, M. B. (2013). Patrimonios de consenso/disenso: De la despolitización a la valoración política de los procesos de patrimonialización. Boletín de Antropología, 28(46), 79-99.

La Casa Curutchet, la joya de La Plata que es patrimonio de la humanidad. (2018, enero 2). Clarín. https://www.clarin.com/ ciudades/casa-curutchet-joya-plata-patrimonio-humanidad_0_ B1A2eySpW.html

Lai, S., \& Can-Seng, O. (2015). Branded as a world heritage city: The politics afterwards. Place Branding and Public Diplomacy, 11(4), 276-292. http://dx.doi.org/10.1057/pb.2015.12

La Lonja de Valencia es declarada patrimonio cultural de la humanidad. (1996, diciembre 5). Las Provincias. http://valenpedia. lasprovincias.es/historiavalencia/1996/la_lonja_de_valencia_ es_declarada_patrimonio_cultural_de_la_humanidad

Lander, E. (Org.). (2000). La colonialidad del saber: Eurocentrismo y ciencias sociales perspectivas latinoamericanas. CLACSO.

Las fallas ya son patrimonio de la humanidad. (2016, diciembre 13). Levante: El Mercantil Valenciano. https://www.levanteemv.com/fallas/2016/11/30/fallas-patrimonio-humanidadunesco/1498820.html

Lo declaró la UNESCO. El filete porteño ya es patrimonio de la humanidad. (2015, enero 12). Clarin. https://www.clarin. com/cultura/filete-filete_porteno-patrimonio_inmaterialpatrimonio_de_la_humanidad-unesco_0_H1W $p c 1 Y$ P7x. html

Martín-Barbero, J. (1998). Patrimonio: El futuro que habita la memoria. http://convenioandresbello.org/cab/wp-content/ uploads/2019/06/Patrimonio.pdf
Martín-Barbero, J. (2000). Dislocaciones del tiempo y nuevas topografías de la memoria. In H. B. Hollanda \& B. Resende (Eds.), Artelatina: cultura, globalização e identidades (pp. 139169). Aeroplano Editora.

Meskell, L. (2013). UNESCO's world heritage convention at 40: Challenging the economic and political order of international heritage conservation. Current Anthropology, 54(4), 483-494. https://doi.org/10.1086/671136

Meskell, L., \& Brumann, C. (2015). UNESCO and new world orders. In L. Meskell (Ed.), Global Heritage: A reader (pp. 22-42). John Wiley \& Sons.

Meskell, L., Liuzza, C., Bertacchini, E., \& Saccone, D. (2015). Multilateralism and UNESCO world heritage: Decisionmaking, states parties and political processes. International Journal of Heritage Studies, 21(5), 423-40.

Ministerio de Cultura y Deport. (n.d.). Somos patrimonio [Video]. http://www.somospatrimonio.es/patrimonio/\#

Montenegro, M. (2010). La patrimonialización como protección contra la mercantilización: Paradojas de las sanciones culturales de lo igual y lo diferente. Revista Colombiana de Antropología, 46(1), 115-131.

Montenegro, M. (2013). Articulaciones entre políticas económicas y políticas culturales en Colombia: El patrimonio cultural, el sector artesanal y las nuevas formas del valor y la propiedad. Boletín de Antropología, 28(46), 35-52.

Monterrosas, M. [@Monterrosas]. (2019, abril 21). Gastronomía, cultura, arte, diversión y muchas cosas más. Twitter https:// twitter.com/Monterrrosas/status/1120141083407556608

Nielsen, B. (2011). UNESCO and the 'right' kind of culture: Bureaucratic production and articulation. Critique of Anthropology, 31(4), 273-292. https://doi.org/10.1177\%2F0308275X11420113

No es un sueño, somos Patrimonio. (2016, diciembre 14). Junta Central Fallera. http://www.fallas.com/index.php/es/mainnoticias-es/main-noticias-organizacion-es/2976-no-es-unsueno-somos-patrimonio

Olé por el flamenco: Ya es patrimonio cultural inmaterial de la humanidad. (2010, noviembre 16). El confidencial. https:// www.elconfidencial.com/cultura/2010-11-16/ole-porel-flamenco-ya-es-patrimonio-cultural-inmaterial-de-lahumanidad_420643/

Organización de las Naciones Unidas para la Educación, la Ciencia y la Cultura. (1972). Convención sobre la protección del patrimonio mundial, cultural y natural. https://whc.unesco.org/archive/ convention-es.pdf

Organización de las Naciones Unidas para la Educación, la Ciencia y la Cultura. (2003). Convención para la salvaguardia del patrimonio cultural inmaterial. https://unesdoc.unesco.org/ ark:/48223/pf0000132540_spa 
Organización de las Naciones Unidas para la Educación, la Ciencia y la Cultura. (2009). Lista representativa del patrimonio cultural inmaterial de la humanidad. https://ich.unesco.org/doc/ src/06859-ES.pdf

Organización de las Naciones Unidas para la Educación, la Ciencia y la Cultura. (2010). Fifth session of the intergovernmental Committee (5. COM)- Nairobi, Kenya, 15 to 19 november 2010. https://ich. unesco.org/es/5com

Palmié, S., \& Stewart, C. (2016). Introduction: For an anthropology of history. HAU: Journal of Ethnographic Theory, 6(1), 207-236. https://doi.org/10.14318/hau6.1.014

Pavone, V. (2008). From the labyrinth of the world to the paradise of the heart: Science and humanism in UNESCO's approach to globalization. Lexington.

Poulot, D. (2006). Une histoire du patrimoine en Occident, XVIII-XIX siècle: Du monuments aux valeurs. Presses Universitaires de France.

Prats, L. (1997). Antropología y patrimonio. Ariel.

Prats, L., \& Santana, A. (Coords.). (2011). Turismo y patrimonio: Entramados narrativos. PASOS.

Prieto, M. (1984, noviembre 5). La UNESCO incluye por primera vez monumentos españoles en la lista de bienes del patrimonio mundial. El País. https://elpais.com/diario/1984/11/05/ cultura/468457201_850215.html

Quijano, A., \& Wallerstein, I. (1992). Elementos del desarrollo: la americanidad como concepto o América en el moderno sistema mundial. Revista Internacional de Ciencias Sociales, (134), 583-591.

Reglamento. (1998). "Obras maestras del patrimonio oral e inmaterial de la humanidad". https://unesdoc.unesco.org/ark:/48223/ pf0000114238

Richards, G. (2014). Tourism trends: The convergence of culture and tourism. Academy for Leisure, NHTV University of Applied Sciences.

Richards, G. (2019). Culture and tourism: Natural partners or reluctant bedfellows? a perspective paper. Tourism Review, 75(1), 232-234. http://dx.doi.org/10.1108/TR-04-2019-0139

Roigé, X., \& Frigolé, J. (Eds.). (2010). Constructing cultural and natural heritage: Parks, Museums and Rural Heritage. Institut Català de Recerca en Patrimoni Cultural.

Roldán, V. A. (2010, diciembre 3). Acto de celebración del Patrimonio Cultural Inmaterial de la Humanidad en España en el MNCARS. Plataforma de Arte Contemporáneo. https:// wWw. plataformadeartecontemporaneo.com/pac/actode-celebracion-del-patrimonio-cultural-inmaterial-de-lahumanidad-en-espana-en-el-mncars/
Ruiz Lanuza, A., \& Pulido, J. (2015). El impacto del turismo en los Sitios Patrimonio de la Humanidad. Una revisión de las publicaciones científicas de la base de datos Scopus. PASOS. Revista de Turismo y Patrimonio Cultural, 13(5), 1247-1264.

Ryan, J., \& Silvanto, S. (2010). World heritage sites: The purposes and politics of destination branding. Journal of Travel \& Tourism Marketing, 27(5), 533-545. https://doi.org/10.1080/105484 08.2010 .499064

Ryan, J., \& Silvanto, S. (2011). A Brand for all the nations: The development of the world heritage brand in emerging markets. Marketing Intelligence \& Planning, 29(3), 305-318.

Said, I. G. (2017). The heritage of al-Andalus and the formation of Spanish history and identity. International Journal of History and Cultural Studies, 3(1), 1-15. dx.doi.org/10.20431/24547654.0301008

Sánchez-Carretero, C. (2017). Hacia una antropología del conflicto aplicada al patrimonio. In B. Santamarina (Ed.), Geopolíticas patrimoniales: De culturas, naturalezas e inmaterialidades- una mirada etnográfica (pp. 215-230). Germania-AVA.

Sánchez-Carretero, C., Múñoz-Albaladejo, J., Ruiz-Blanch, A., \& Roura-Expósito, J. (Eds.). (2019). El imperativo de la participación en la gestión patrimonial. CSIC.

Santamarina, B., \& Del Mármol, C. (2017). Ciudades creativas y pueblos con encanto: Los nuevos procesos patrimoniales del siglo XXI. Revista de Dialectología y Tradiciones Populares, 72(2), 359-377. https://doi.org/10.3989/rdtp.2017.02.003

Santamarina, B., \& Del Mármol, C. (2020). Para algo que era nuestro... ahora es de toda la humanidad: El patrimonio mundial como expresión de Conflictos. Chungará-Revista de Antropología Chilena, 52(1), 161-173. http://dx.doi.org/10.4067/ S0717-73562020005000301

Santamarina, B., \& Del Mompó, E. (2021). The political opportunity of heritage: Appropriations, memories and identities in Cabanyal. Anthropological Quarterly, 94(2), 313-344. https:// doi.org/10.1353/anq.2021.0004

Schmitt, T. (2008). The UNESCO concept of safeguarding intangible cultural heritage: Its background and Marrakchi roots. International Journal of Heritage Studies, 14(2), 95-111. https:// doi.org/10.1080/13527250701844019

Schmitt, T. (2009). Global cultural governance: Decision-making concerning world heritage between politics and science. Erdkunde, 63(2), 103-121.

Smith, L. (2006). Uses of heritage. Routledge.

Smith, L. (2008). Heritage, gender and identity. In B. Graham \& P. Howard (Eds.), The ashgate research companion to heritage and identity (pp. 159-178). Ashgate Publishing. 
iiiiiiiiiiiisomos Patrimonio de la Humanidad!!!!!!!!. (2010, noviembre). Paco de Lucía: foro oficial. http://www. pacodelucia. org/foro/viewtopic. php? $\mathrm{f}=7 \& \mathrm{t}=851 \&$ start $=0$

Stoczkowski, W. (2009). UNESCO's doctrine of human diversity: a secular soteriology? Anthropology Today, 25(3), 7-11. http:// dx.doi.org/10.1111/j.1467-8322.2009.00666.x

Tauschek, M. (2013). The bureaucratic texture of national patrimonial policies. In R. F. Bendix, A. Eggert \& A. Peselmann (Eds.), Heritage regimes and the state (pp. 195-212). Göttingen University Press.

Timothy, D. J. (2018). Making sense of heritage tourism: Research trends in a maturing field of study. Tourism Management Perspectives, 25, 177-180. https://doi.org/10.1016/j. tmp.2017.11.018

United Nations Educational, Scientific and Cultural Organization. (2011, noviembre 29). Sixth session of the intergovernmental Committee (6.COM) - Bali, Indonesia, November 2011. https:// ich.unesco.org/en/6com
United Nations Educational, Scientific and Cultural Organization. (2012, diciembre 7). Seventh session of the intergovernmental Committee (7.COM). https://ich.unesco.org/en/7com

Villarroya, A. A. (2002). La expansión del patrimonio cultural. Revista de Occidente, (250), 129-150.

Winter, T. (2014). Beyond eurocentrism? Heritage conservation and the politics of difference. International Journal of Heritage Studies, 20(2), 123-137. https://doi.org/10.1080/13527258.2 012.736403

World Heritage Centre. (n.d.). Sustainable Tourism. http://whc. unesco.org/en/tourism/

World Tourism Organization. (2018). Tourism and culture synergies. UNWTO.

\section{CONTRIBUCIÓN DE LOS AUTORES}

B. Santamarina contribuyó con conceptualización, selección de datos, análisis formal, adquisición de financiación, investigación, metodologia, administración de proyectos, recursos, supervisión, validación, visualización, borrador del escrito original, revisión del escrito y edición; y C. del Mármol con conceptualización, selección de datos, análisis formal, adquisición de financiación, investigación, metodologia, administración de proyectos, recursos, software, supervisión, validación, visualización, borrador del escrito original, revisión del escrito y edición. 